https://doi.org/10.1017/ice.2018.141 Published online by Cambridge University Press 


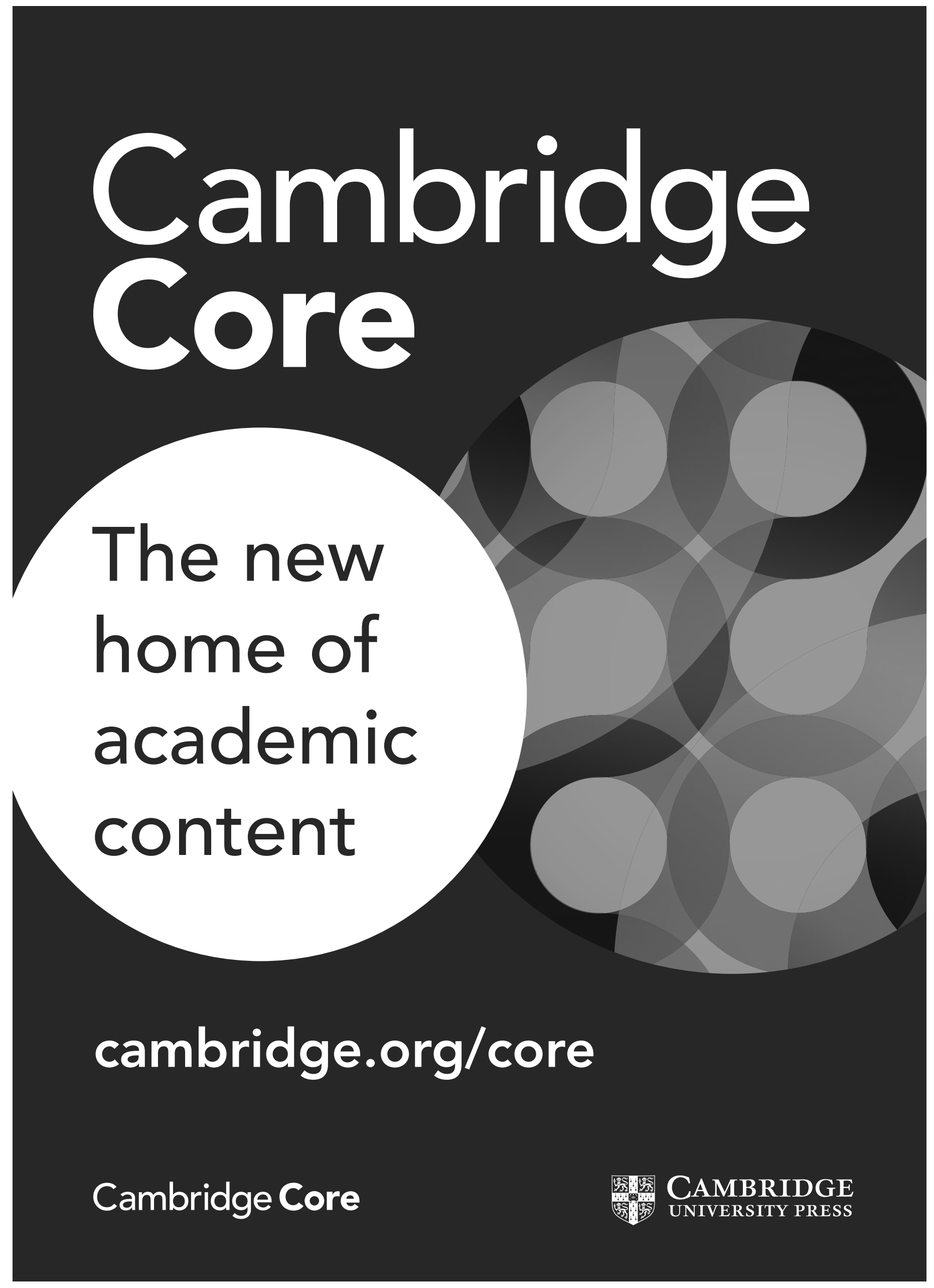




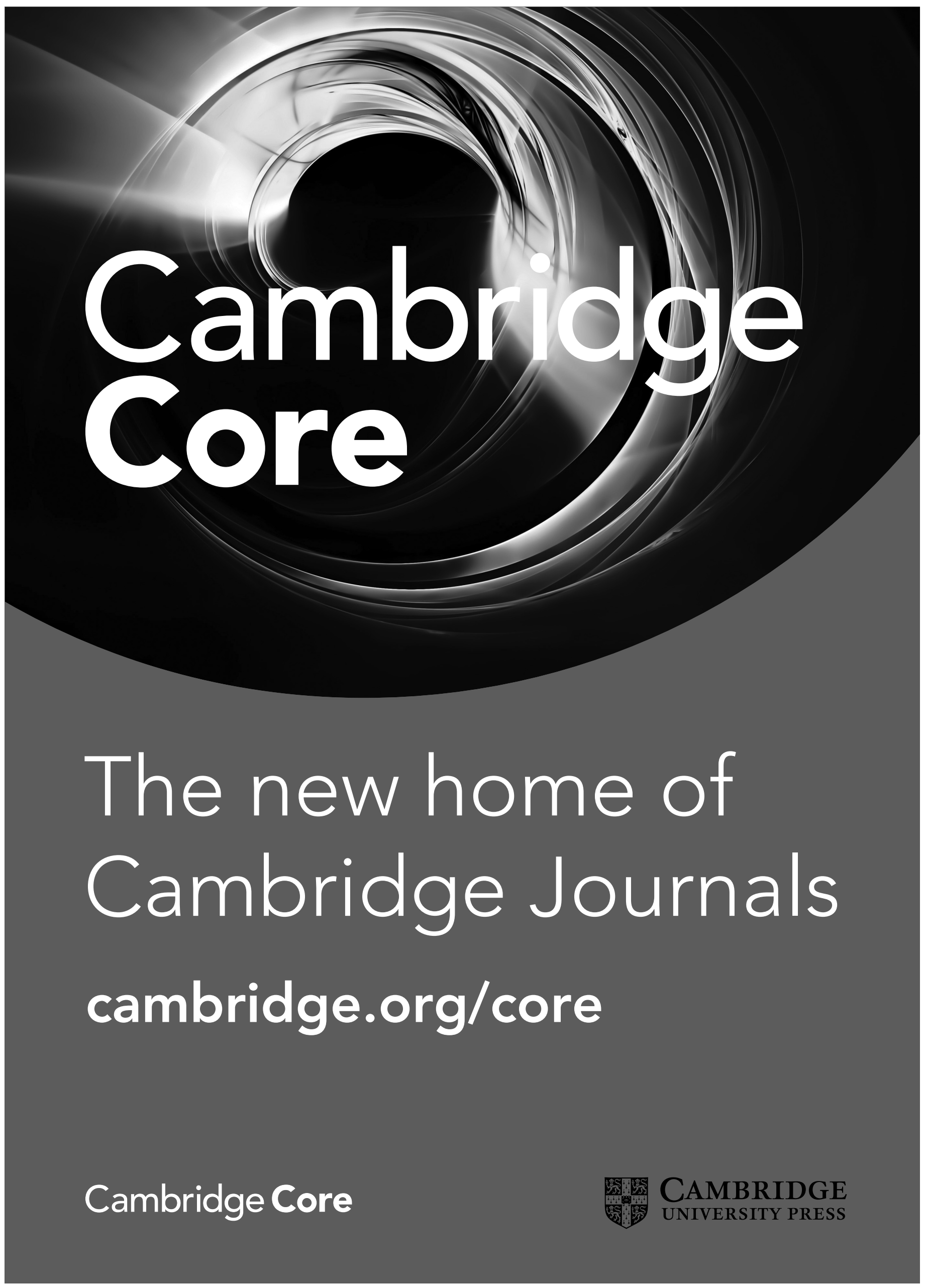


Access

leading

journals in

your subject

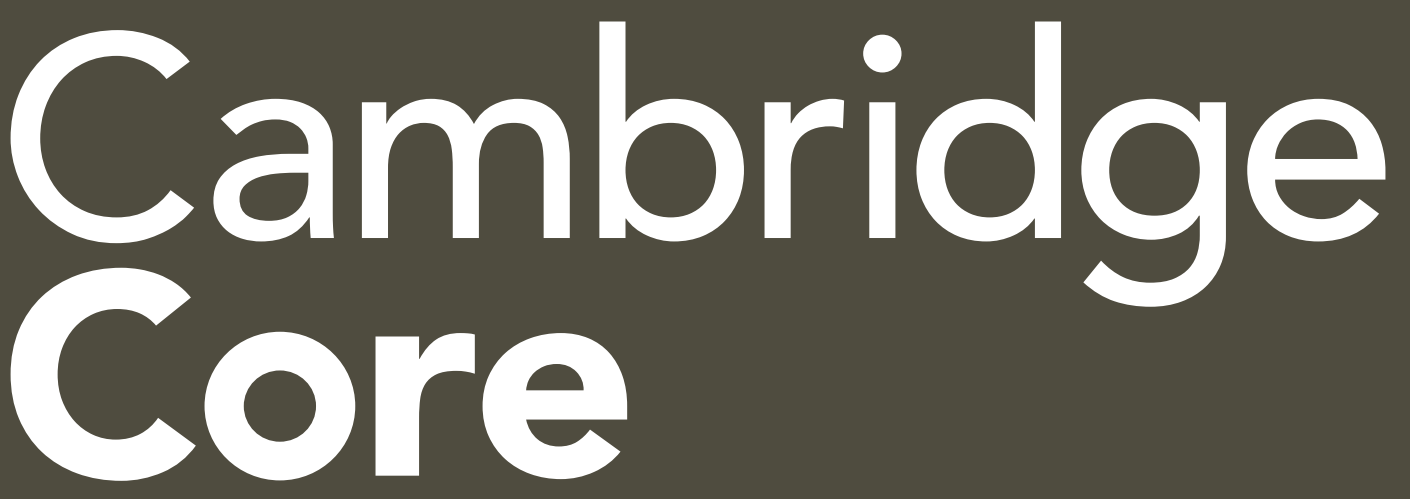

Explore today at cambridge.org/core

Cambridge Core 


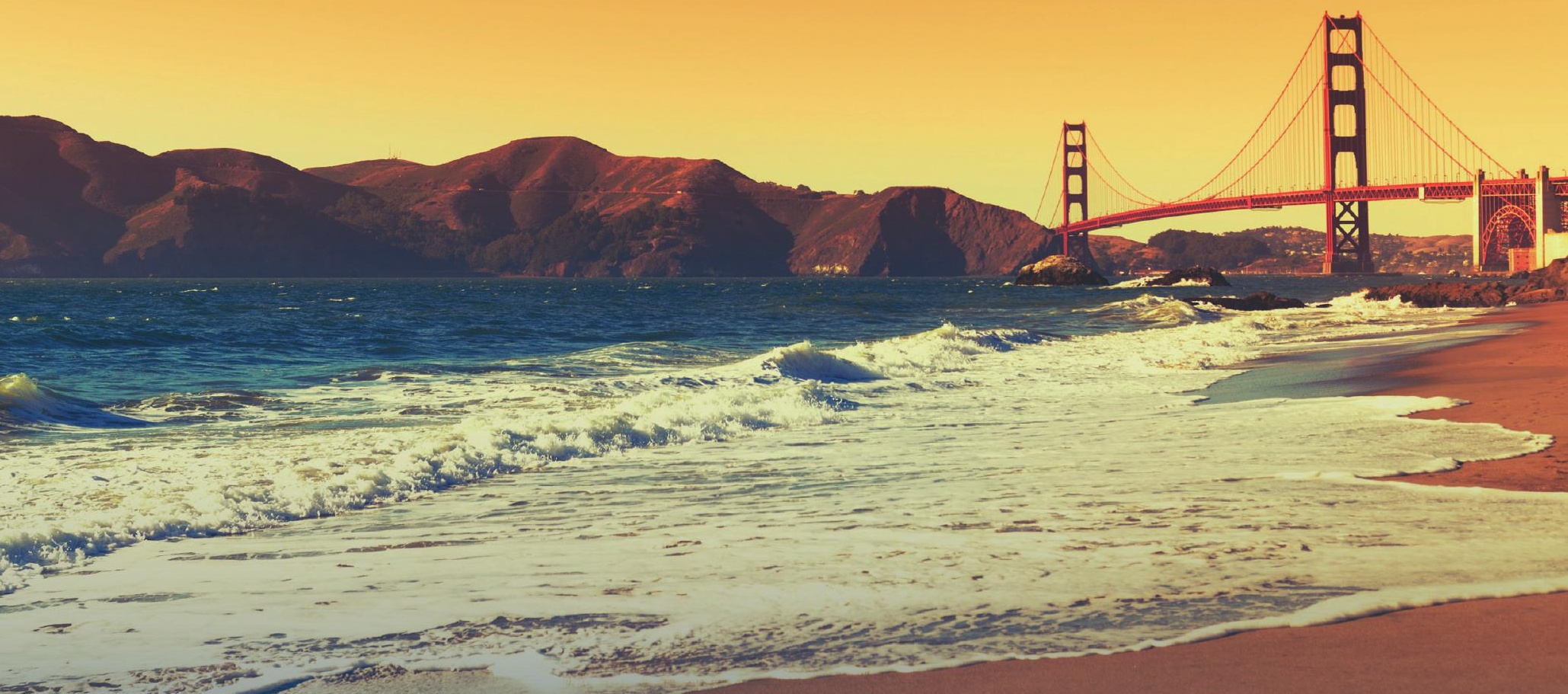

Don't miss

the premier

international

infectious

diseases

meeting of

the year
October 3-7 • San Francisco, CA • www.idweek.org

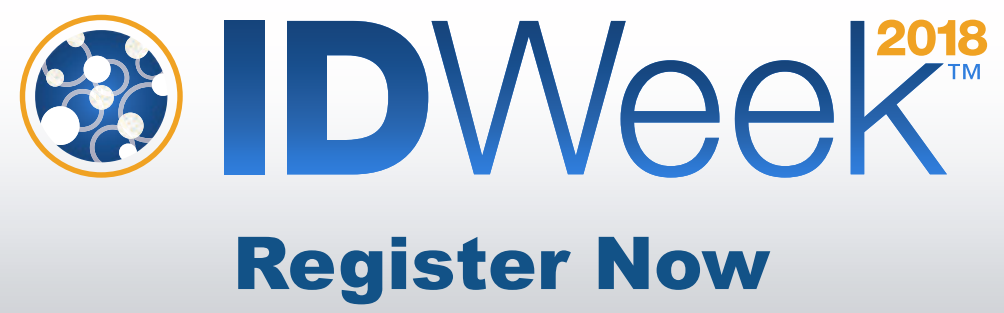

Pre-Registration Discount Ends September 7

\section{Accepting Late Breaker Abstracts}

Deadline August 16

A JOINT MEETING OF 